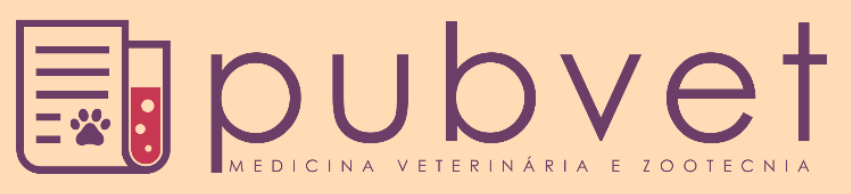

https://doi.org/10.31533/pubvet.v14n1a482.1-7

\title{
Utilização de retalho de avanço em tumor de cabeça e pescoço em um cão: relato de caso
}

\author{
Debora Flaminio Zoia ${ }^{\bullet}$, Bruno de Tulho Augusto Roque Lima ${ }^{2}$, Larissa Ebel Pacifico Negrão ${ }^{3}$ \\ Caroline Corrêa de Tulio Augusto Roque ${ }^{4}$, Gustavo Marques Abreu Serrão ${ }^{50}$ \\ ${ }^{1}$ Graduanda Medicina Veterinária - São Judas Tadeu, Santos/SP Br \\ ${ }^{2}$ Medico Veterinário, Mestre em Cirurgia, Doutor em Oncologia, professor pelo Instituto Qualittas de Pós-Graduação,Campinas/SP Br. \\ ${ }^{3}$ Graduanda Medicina Veterinária - São Judas Tadeu, Santos/SP Br. \\ ${ }^{4}$ Médica Veterinária, Imagenologista na Clínica de Imagem Ômega, Santos/SP Br \\ ${ }^{5}$ Médico Veterinário, Residência em Anestesiologia - Universidade Metropolitana de Santos, Unimes; Santos/SP Br. \\ *Autor para correspondência, E-mail: deflaminioz@gmail.com
}

\begin{abstract}
Resumo. O termo cirurgia reconstrutivo, faz referência à utilização de diferentes técnicas de reconstrução tecidual, como suturas, incisões, retalhos (flaps) e enxertos, na correção de defeitos de pele traumáticos, quando o fechamento primário não é possível devido a um excesso de tensão no tecido. A face, quando intervencionada cirurgicamente, é frequentemente sede de reconstruções plásticas, uma vez que se torna impossível o encerramento primário da ferida cirúrgica sem o aparecimento de linhas de tensão excessivas que comprometam quer a cicatrização, quer a funcionalidade das estruturas adjacentes ao defeito, como por exemplo, as pálpebras ou a boca. Objetivou-se descrever o caso de um canino, fêmea com nódulo ulcerado em região de lábio superior.
\end{abstract}

Palavras chave: flap, cirúrgica reconstrutiva, tumor

\section{Use of advance flap in head and neck tumor in a dog: Case report}

\begin{abstract}
The term reconstructive surgery refers to the use of different tissue reconstruction techniques, such as sutures, incisions, flaps and grafts, in the correction of traumatic skin defects, when primary closure is not possible due to an excess of tension in the fabric. The face, when surgically intervened, is often the site of plastic reconstruction, since primary closure of the surgical wound becomes impossible without the appearance of excessive tension lines that compromise both healing and the functionality of structures adjacent to the defect, such as for example, the eyelids or the mouth. This study aimed to describe the case of a female canine with ulcerated nodule in the upper lip region.
\end{abstract}

Keywords: flap, reconstructive surgery, tumor

\section{Uso de Flap avanzado en tumor de cabeza y cuello en un perro: Reporte de un caso}

Resumen. El término cirugía reconstructiva se refiere al uso de diferentes técnicas de reconstrucción de tejidos, como suturas, incisiones, colgajos e injertos, en la corrección de defectos cutáneos traumáticos, cuando el cierre primario no es posible debido a la tensión excesiva en el tejido La cara, cuando se interviene quirúrgicamente, es a menudo um sitio de reconstrucciónes plásticas, ya que el cierre primario de la herida quirúrgica se vuelve imposible sin la aparición de líneas de tensión excesiva que comprometan la cicatrización y la funcionalidad de las estructuras adyacentes al defecto, como por ejemplo, los párpados 
o la boca. Este estudio tuvo como objetivo describir el caso de un canino femenino con nódulo ulcerado en la región del labio superior.

Palabras clave: flap, cirugía reconstructiva, tumor

\section{Introdução}

Nas últimas décadas têm sido desenvolvidas inúmeras e inovadoras técnicas para a exérese cirúrgica de neoplasias. Paralelamente, registaram-se avanços igualmente importantes no campo da reconstrução dos defeitos resultantes da natureza ablativa das cirurgias praticadas em oncologia (Daleck et al., 2016; Fineman, 2004; Rosenthal, 2004). A cirurgia reconstrutiva, faz referência a utilização de diferentes técnicas de reconstrução tecidual, como suturas, incisões, retalhos (flaps) e enxertos, na correção de defeitos de pele traumáticos, quando o fechamento primário não é possível devido a um excesso de tensão no tecido. As cirurgias reconstrutivas têm a intenção de restaurar a anatomia local, corrigindo perdas ou disfunções, tanto motoras quanto sensitivas (Daleck et al., 2016; Fossum, 2014; Ritter, 2018; Slatter, 2007). A cirurgia reconstrutiva na Medicina Veterinária entra como um auxílio para pacientes oncológicos, para ter sua região operada reconstruída minimizando assim, traumas, mutilações, perdas de funções onde outrora havia tumores. São vários os métodos de reconstrução tecidual. Para a escolha da técnica mais adequada a ser utilizada, alguns fatores devem ser considerados, a localização da ferida, tamanho, as linhas de tensão, disponibilidade de pele, elasticidade do tecido adjacente, suprimento sanguíneo regional e principalmente a preferência e experiência do cirurgião quanto à técnica a ser utilizada, devem ser avaliados (Fossum, 2014; Ritter, 2018; Withrow et al., 2014).

Das regiões do corpo do cão e do gato onde ocorrem tumores, cabeça e pescoço, são as mais desafiadoras. Uma vez que é difícil atingir margens de segurança nessas regiões por conta da proximidade de estruturas e tecidos importantes, que devem ser preservados. $\mathrm{O}$ que faz com que cabeça e pescoço sejam alvos de novos estudos de técnicas de reconstrução.

Segundo Brønden et al. (2009), cânceres de cabeça e pescoço são doenças relativamente comuns e muitas vezes muito graves em cães e humanos. As neoplasias são classificadas basicamente em malignas e benignas, de acordo com as diferentes características bioquímicas, morfológicas e funcionais (De Nardi et al., 2002). Apesar das benignas causarem morbidez tecidual direta, não resulta em elevada mortalidade. Em contrapartida, as malignas causam maior destruição no tecido e geralmente levam o animal a óbito (Withrow et al., 2014). Dentre todas as neoplasias, aproximadamente 38,4 \% são malignas e 46,7 \% benignas. Os tipos mais comuns de neoplasia maligna são carcinoma de celulas escamosas ( $28 \%$ dos malignos), sarcoma de tecidos moles (17\% dos malignos), adenocarcinoma (11\% dos malignos) e melanomas (2,65 \%). Dentre os tipos mais comuns de neoplasias benignas estão adenoma ( $16 \%$ dos benignos), pólipo ( $14 \%$ dos benignos) e fibroma (11\% dos benignos) (Brønden et al., 2009).

Conhecer a fase evolutiva da doença é tão importante para o planeamento terapêutico, para a emissão de um prognóstico como conhecer a sua identidade. Considerando este facto, foram desenvolvidos sistemas de estadiamento de tumores que, além de serem ferramentas muito úteis na clínica diária, geram a uniformidade necessária para que seja possível comparar as respostas terapêuticas em indivíduos diferentes (Goldschmidt \& Hendrick, 2002; Meuten, 2002). Para que o prognóstico seja favorável, isto é, a probabilidade de recidiva tumoral seja menor, faz-se necessário a ressecção cirúrgica com ampla margem de segurança, o que pode englobar tecido ósseo, dentes, lábios e globo ocular (Dias et al., 2015; Withrow et al., 2014), assim, como a realização da linfadenectomia, devido à alta incidencia de envolvimento linfonodal. A linfadenectomia pode desempenhar um papel importante em nossos pacientes oncologicos no que diz respeito ao estadiamento clínico, determinando o prognóstico, desenvolvendo planos de tratamento e diminuindo a carga tumoral. Para uma dada doença oncológica, os linfonodos regionais periféricos devem ser cuidadosamente palpados para ampliação, assimetria e grau de fixação. Embora a identificação de linfonodos aumentados de forma palpável seja tipicamente direta, a identificação e extirpação de linfonodos periféricos quando eles são de tamanho normal podem ser desafiadores. A palpação anormal do linfonodo pode ser útil para levantar suspeita de metástase. No entanto, o julgamento clínico em relação às metástases para os linfonodos locais não deve ser baseado apenas na palpação, já que o tamanho dos linfonodos não é um prognóstico preciso de metástase (Wright \& Oblak, 2016). 
A face, quando intervencionada cirurgicamente, é frequentemente sede de reconstruções plásticas, uma vez que se torna impossível o encerramento primário da ferida cirúrgica sem o aparecimento de linhas de tensão excessivas que comprometam quer a cicatrização, quer a funcionalidade das estruturas adjacentes ao defeito como, por exemplo, as pálpebras ou a boca (Fossum, 2014; Nelson \& Couto, 2015). Além de assegurar a função das estruturas anatómicas lesionadas, o cirurgião deverá também considerar o aspeto estético, de modo a reduzir o impacto psicológico que a aparência do doente poderá induzir ao cuidador após a intervenção cirúrgica (Bojrab, 2005; Niebauer, 1993; Pope, 2006).

As lesões labiais têm a sua origem frequentemente em cirurgia oncológica, traumatismos ou alterações congénitas (Benlloch-Gonzalez et al., 2013). As técnicas de reconstrução local incluem técnicas de exérese em triângulo ou retângulo, retalhos subdérmicos de avanço, rotação bucal e retalhos de modelo axial (Kudnig \& Séguin, 2012; Ritter, 2018).

O objetivo deste trabalho é relatar uma paciente canina com um tumor em região rostral de focinho que foi reconstruído com retalho de avanço de plexo sub-dérmico e um paciente felino também com um tumor em lábio superior com envolvimento de palato que foi reconstruído com retalho de padrão axial da artéria angula da boca.

\section{Relato de caso}

Foi atendido, no hospital veterinário Mar a Pet, localizado em Santos, São Paulo, no dia 5 de fevereiro de 2019, um canino, fêmea da raça Rottweiler, com nove anos de idade, pesando $59 \mathrm{~kg}$, apresentando um nódulo ulcerado não aderido com evolução progressiva há mais de seis meses, em região de lábio superior com diâmetro aproximado de seis $\mathrm{cm}$ (Figura 1A). Foram solicitados exames de perfil básico, eritrograma e leucograma e bioquímica sérica. Constou-se aumento na creatinina e ureia, resultando em $1,8 \mathrm{mg} / \mathrm{dL}$ e $71 \mathrm{mg} / \mathrm{dL}$, respectivamente. No eritrograma, a série vermelha estava baixa apresentando resultados de 10,2 g/dL de hemoglobina e 30,6\% de hematócrito. No leucograma, notou-se monocitose com valores respectivos de 2.130. No exame ultrassonográfico descobriu-se uma esplenomegalia. Ainda, observou-se uma formação arredondada em região de cauda esplênica compatível com neoformação e espessamento das paredes da bexiga medindo $0,30 \mathrm{~cm}$ compatível com cistite.

Para o procedimento cirúrgico, no dia 14 de fevereiro de 2019, foi solicitado, que o paciente comparecesse a clínica, em jejum alimentar de oito horas e hídrico de seis horas. Como protocolo préanestésico, utilizou-se cetamina $(5 \mathrm{mg} / \mathrm{kg})$, midazolam $(0,5 \mathrm{mg} / \mathrm{kg})$ e metadona $(0,3 \mathrm{mg} / \mathrm{kg})$, pela via intramuscular. Indução de propofol $(2,5 \mathrm{mg} / \mathrm{kg})$, também por via intravenosa, manutenção com isuflorano (por infusão contínua) por via inalatória. No transoperatório foram utilizados quetamina (5 $\mathrm{mg} / \mathrm{kg}$ ) e infusão contínua de fentanil. Foi realizado o bloqueio no nervo infra-orbitário com bupivacaina $(5 \mathrm{mg} / \mathrm{mL})$. Posterior à aplicação da MPA, foi realizado acesso venoso, na veia cefálica, para fluidoterapia, realizada com solução de ringer com lactato e um equipo macrogotas $(5 \mathrm{~mL} / \mathrm{kg} / \mathrm{h})$. Também foi realizada tricotomia ampla na região rostral. Após a indução anestésica, o paciente foi intubado, com sonda endotraqueal de $\mathrm{n}^{\circ} 10$ e mantido em sistema semiaberto. $\mathrm{O}$ monitor multiparamétrico foi conectado ao paciente, para avaliação do eletrocardiograma, pressão arterial invasiva (PAI), fração expirada de oxigênio (ETCO2), saturação parcial de oxigênio (SPO2) e temperatura.

O procedimento cirúrgico iniciou-se com esplenectomia total. Em seguida passou-se para a face. Realizou-se a exérese da neoplasia (Figura 1B). Prosseguiu-se com a incisão de pele para confecção do retalho (Figura 1C). O comprimento do retalho deve ser tão curto quanto possível, de modo a que não haja perturbações na vascularização e a que o encerramento seja realizado sem linhas de tensão excessivas (Pope, 2006). Os retalhos de avanço baseiam-se no avanço linear da peça retalhada numa única direção. Representam os retalhos mais simples e versáteis de realizar. Foi realizado um retalho uni - pediculado (Figura 1D). A largura do retalho deve ser a mesma do que a do defeito enquanto o seu comprimento não deve ser maior que duas vezes a largura do seu pedículo (Figura 1E). A pele foi suturada com fio absorvível sintético monofilamentar (náilon) 3-0 em padrão simples separado (Figura $\underline{1 F})$. Ao término da sutura não se observou nenhum desvio ou deformação anatômica. Foi realizada a linfadenectomia dos linfonodos mandibulares. Juntamente ao tumor de face, o tumor em baço e linfonodos foram enviados para análise histopatológica para o laboratório São Miguel. 
Foram administrados hidrocortizona ( $10 \mathrm{mg} / \mathrm{kg})$, metronidazol $(25 \mathrm{mg} / \mathrm{kg})$, ceftriaxona $(30 \mathrm{mg} / \mathrm{kg})$ por via intravenosa e metadona $(0,3 \mathrm{mg})$ no pós-operatório. O paciente foi monitorado até completa recuperação anestésica e encaminhado para casa, juntamente com prescrição de antibióticos e recomendação de uso de colar elisabetano e fornecimento de alimento pastoso por 15 dias até a retirada dos pontos cutâneos (Figura 1H e Figura 1G).

No histopatológico realizado foi obtido o diagnóstico sarcoma de partes moles na face, sendo observadas 34 figuras de mitose em 10 campos de 400x com metástase para linfonodos. Baço sem indícios de neoplasia.

Devido a não se ter atingido margem de segurança, houve recidiva em menos de um mês depois após a cirurgia onde a cadela passou por novo procedimento cirúrgico. Atualmente está em acompanhamento.

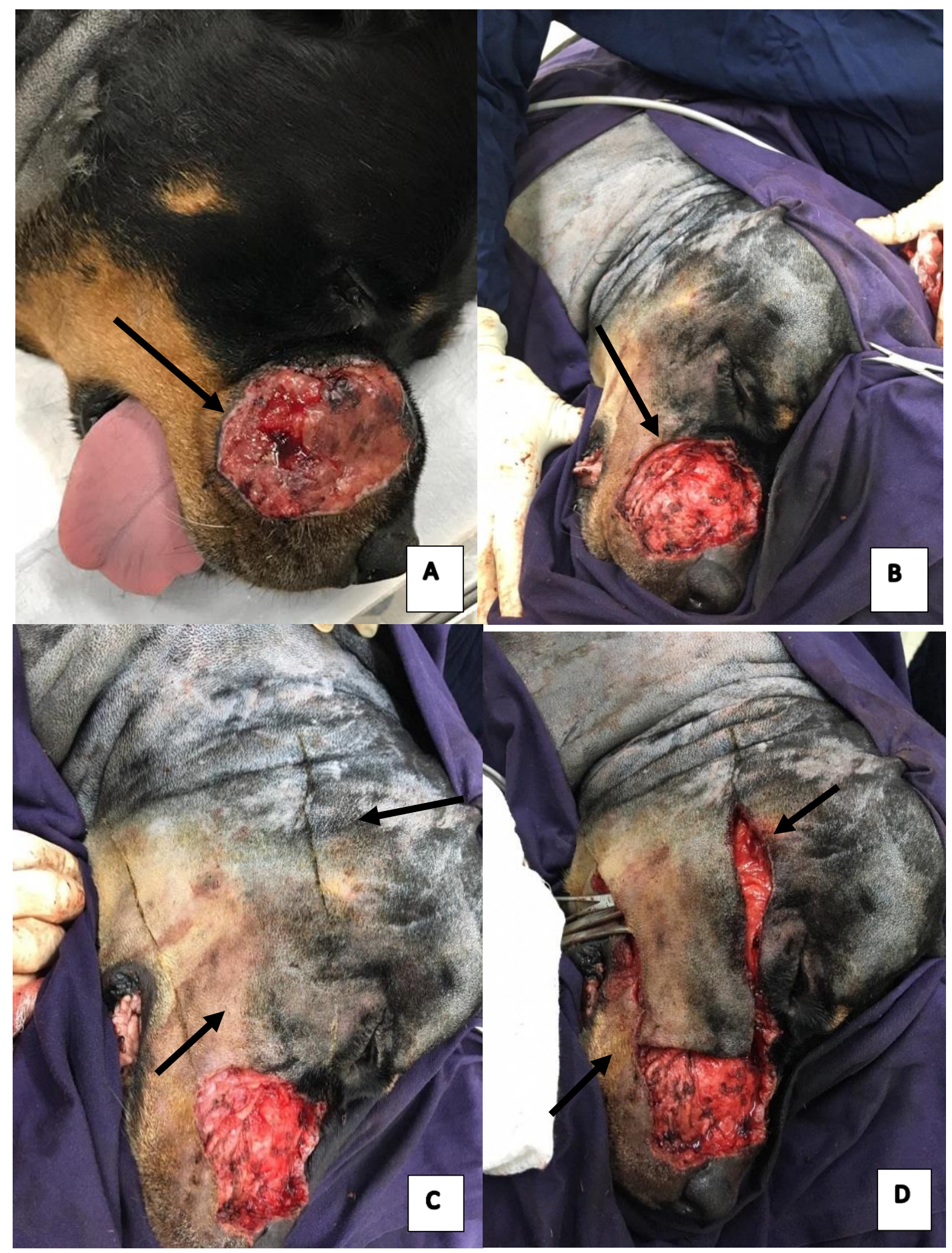




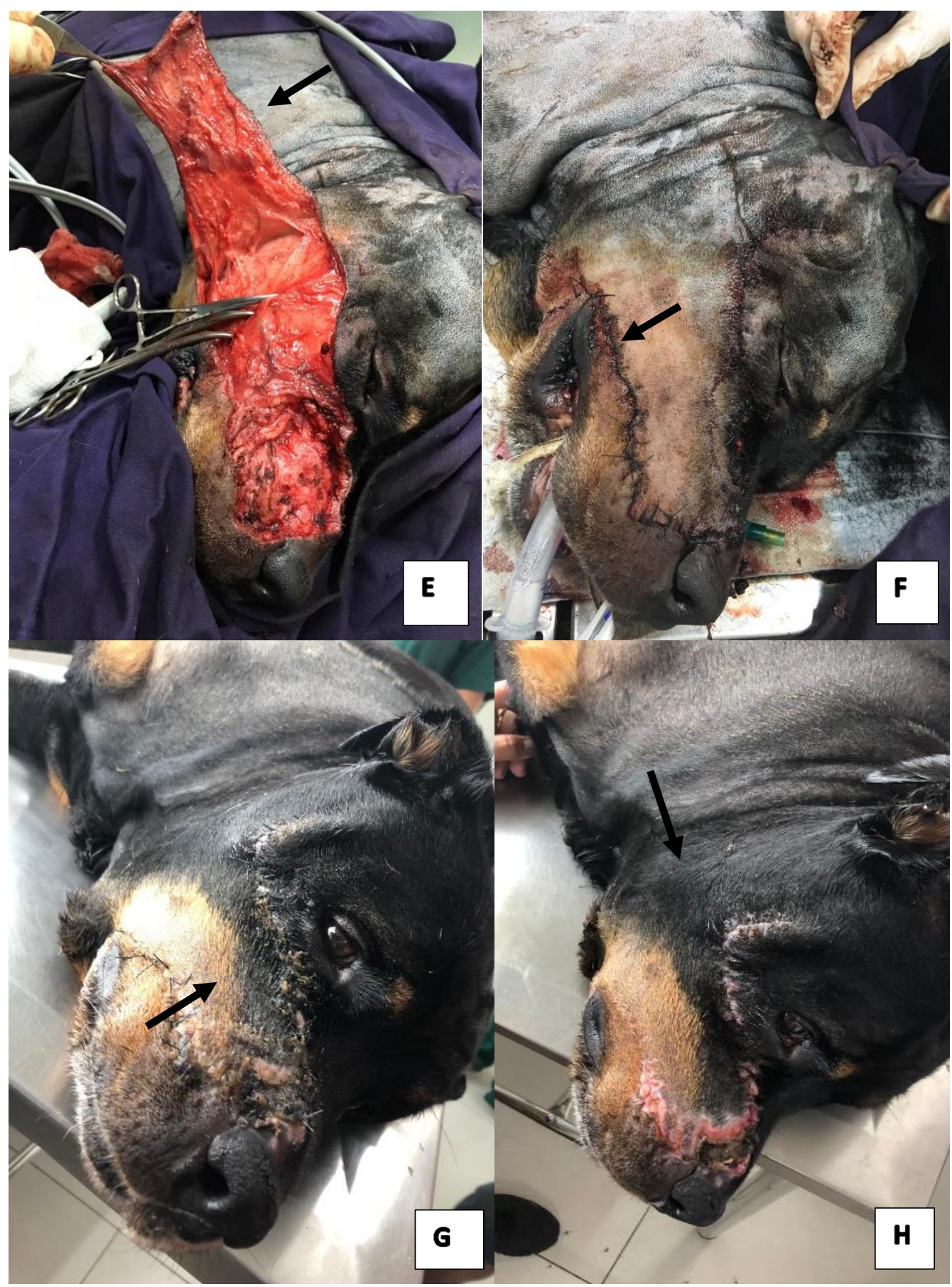

Figura 1. Canina fêmea, Rottweiler, nove anos, apresentando lesão ulcerada em região de lábio superior. (A) Nódulo em região de lábio superior com diâmetro aproximado de seis cm. (B) Após a exérese da neoplasia. (C) Demarcação do retalho. (D) Incisão cirúrgica do retalho unilateral. (E) Largura e comprimento do retalho. (F) Pós-operatório imediato (G) Quinze dias após a cirurgia ainda com os pontos. (H) Quinze dias após a cirurgia depois da retirada de pontos. Arquivo pessoal, 2019. Arquivo pessoal, 2019.

\section{Discussão}

Os sarcomas de tecidos moles (STM) são neoplasias mesenquimais malignas provenientes de tecidos conjuntivos e são caracterizados pela alta infiltração local, como visto em ambos os casos relatados. Sua ocorrência é mais frequentes em animais de meia idade e idosos, não tendo predileção sexual ou racial, entretanto alguns autores apontam sua maior ocorrência em cães de médio e grande porte como ocorrido no caso (Sisson et al., 1986). Os fibrossarcomas são considerados as neoplasias mesenquimatosas malignas mais comuns nos gatos (Francisco et al., 2008; Priebe et al., 2011). 
Houve metástase linfonodal, mesmo Liptak \& Withrow (2007), citando que normalmente apresentam baixo potencial metastático e raramente metastatizando para linfonodos. Não foi possível a retirada do tumor com completa margem cirúrgica, por ser um tumor de margens mal definidas e ser localmente invasivo, assim como citado por Davis et al. (2007). Segundo Davis et al. (2007) é um tumor que possuí elevada taxa de recidiva, assim como ocorrido no presente caso onde houve recidiva da neoplasia em menos de um mês. Segundo Daleck et al. (2016) o alto índice mitótico está associado a recidiva, onde podemos observar no histopatológico de 34 figuras de mitose em 10 campos de $400 \mathrm{x}$. O tratamento de escolha foi à excisão cirúrgica, conforme sugerem Scott et al. (2001) e Daleck et al. (2016). É frequente a necessidade de técnicas reconstrutivas, para o fechamento das feridas criadas pela extirpação desses tumores. Hedlund (2008) e Daleck et al. (2016), quando compararam o uso dos enxertos livres com os retalhos locais, observaram que nos retalhos as chances de se obter resultado são maiores do que com os enxertos, já que estes não apresentam um pedículo vascularizado, como acontece com os retalhos, o que os torna uma escolha mais adequada para este caso. O retalho escolhido foi o retalho de avanço de plexo sub-dérmico. Segundo Pope (2006), a largura do retalho sub-dérmico deve ser igual à do defeito e seu comprimento deve ser o suficiente para permitir o encerramento sem tensão assim como realizado no procedimento cirúrgico. O comprimento do retalho não deve ser superior ao dobro da sua largura, como foi respeitado pelo cirurgião, caso isso não ocorra há grandes chances de necrose tecidual (Dias et al., 2013; Ritter, 2018). As técnicas reconstrutivas utilizadas variam de acordo com a disponibilidade de pele e o tipo e a localização da ferida (Mota, 2012). A sutura utilizada foi a de ponto simples isolado, sendo uma alternativa rápida e eficaz (Pope, 2006). Foi realizado o histopatológico, de modo a obter um diagnóstico mais preciso e avaliar a perfeição da exérese cirúrgica (Ritter, 2018). A cirurgia pode ser ou não associada com técnicas de controle local, como eletroquimioterapia e radioterapia (Daleck et al., 2016); porém, essas técnicas não foram associadas devido à restrição financeira dos proprietários Não se está bem estabelecida a eficácia do tratamento com quimioterapia em sarcomas de tecidos moles, embora seja indicado seu uso na presença de metástase, porém não foi possível a realização do tratamento por escolha dos tutores. O tumor recidivou após semanas e foi feita a rescisão cirúrgica. $\mathrm{O}$ animal está sendo acompanhado periodicamente e encontra-se clinicamente bem.

\section{Conclusão}

Conclui-se que para ambos os casos o retalho escolhido foi à escolha adequada para a reconstrução cirúrgica, não havendo deiscência ou necrose de pontos.

\section{Referências bibliográficas}

Benlloch-Gonzalez, M., Lafarge, S., Bouvy, B. \& Poncet, C. (2013). Nasal-skin-fold transposition flap for upper lip reconstruction in a French bulldog. The Canadian Veterinary Journal, 54(10):983-986.

Bojrab, M. J. (2005). Técnicas atuais em cirurgia de pequenos animais. São Paulo: Editora Roca.

Brønden, L. B., Eriksen, T. \& Kristensen, A. T. (2009). Oral malignant melanomas and other head and neck neoplasms in Danish dogs-data from the Danish Veterinary Cancer Registry. Acta Veterinaria Scandinavica, 51(1):54.

Daleck, C. R., Fonseca, C. S. \& Canola, J. C. (2016). Oncologia em cães e gatos. Rio de Janeiro: Roca.

Davis, K. M., Hardie, E. M., Lascelles, B. D. X. \& Hansen, B. (2007). Feline fibrosarcoma: perioperative management. Compendium on Continuing Education for the Practicing Veterinarian, 29(12):712732.

De Nardi, A. B., Rodaski, S., Sousa, R. S., Costa, T. A., Macedo, T. R., Rodigheri, S. M., . . Piekarz, C. H. (2002). Prevalência de neoplasias e modalidades de tratamentos em cães, atendidos no hospital veterinário da Universidade Federal do Paraná. Archives of Veterinary Science, 7(2):15-26.

Dias, F., Dias, L., Pereira, L., Cabrini, T. \& Rocha, J. (2015). Neoplasias orais nos animais de companhia-Revisão de literatura. Revista Científica Eletrônica de Medicina Veterinária, 20(1):1-9.

Dias, I. R., Sousa, C. M. P., Carvalho, P. M. P., Lempeck, M. R., Viegas, C. A. \& Azevedo, J. T. (2013). Enxertos e substitutos ósseos em cirurgia ortopédica reconstrutiva nos animais de companhia: uma breve revisão. Revista Brasileira de Medicina Veterinária, 35(4):339-350. 
Fineman, L. S. (2004). Tumores da pele e do tecido subcutâneo em cães e gatos. In R. C. Roshental (Ed.), Segredos em oncologia veterinária (pp. 169-176). Porto Alegre: Artmed.

Fossum, T. W. (2014). Cirurgia de pequenos animais (4 ed. Vol. 1). São Paulo: Elsevier Brasil.

Francisco, M. C., Rocha, J. R., Pena, S. B. \& Lot, R. F. E. (2008). Estudo comparativo de neoplasias cutâneas em cães e gatos atendidos no hospital veterinário da Famed-Garça-SP no período 2003 a 2007. Revista Científica Eletrônica de Medicina Veterinária, 101-7.

Goldschmidt, M. H. \& Hendrick, M. J. (2002). Tumors of the skin and soft tissues. In D. J. Meuten (Ed.), Tumors in domestic animals (pp. 45-117). Iowa, USA: Iowa State Press.

Hedlund, C. S. (2008). Cirurgia dos sistemas reprodutivo e genital. In T. W. Fossum (Ed.), Cirurgia de pequenos animais (pp. 619-672). Rio de Janeiro: Elsevier.

Kudnig, S. T. \& Séguin, B. (2012). Veterinary surgical oncology: John Wiley \& Sons.

Liptak, J. M. \& Withrow, S. J. (2007). Cancer of the gastrointestinal tract. In S. J. Withrow \& D. M. Wail (Eds.), Small animal clinical oncology. (pp. 455-473). St Louis, USA: Saunders Elsevier.

Meuten, D. J. (2002). Tumors of the skin and soft tissues. Iowa: Iowa Satate Press.

Mota, A. K. R. (2012). Integração de retalhos de plexo subdérmico para o recobrimento de feridas traumáticas em membros de cães-Avaliação clínica. Medicina Veterinária, 6(2):1-9.

Nelson, R. W. \& Couto, C. G. (2015). Medicina interna de pequenos animais. Amsterdan: Elsevier Editora.

Niebauer, G. (1993). Técnicas atuais em cirurgia de pequenos animais. In M. J. Bojrab (Ed.), Current Techniques in Small Animal Surgery. Philedelphia: Lea and Febiger.

Pope, E. R. (2006). Head and facial wounds in dogs and cats. Veterinary Clinics: Small Animal Practice, 36(4):793-817.

Priebe, A. P. S., Riet-Correa, G., Paredes, L. J. A., Costa, M. S. F., Silva, C. D. C. \& Almeida, M. B. (2011). Ocorrência de neoplasias em cães e gatos da mesorregião metropolitana de Belém, PA entre 2005 e 2010. Arquivo Brasileiro de Medicina Veterinária e Zootecnia, 63(6):1583-1586.

Ritter, J. L. (2018). Utilização de cirurgia reconstrutiva para oclusão de defeito após exérese de mastocitoma: relato de caso. Trabalho de Conclusão de Curso, Universidade Federal de Santa Catarina, Curitibanos, Santa Catarina, Brasil.

Rosenthal, R. C. (2004). Segredos em oncologia veterinária. Porto Alegre: Artmed.

Scott, D. W., H., M. W. \& E., G. C. (2001). Mullerand Kirk's small animal dermatology. Philadelphia, USA: WB. Saunders.

Sisson, S., Grossman, J. D. \& Getty, R. (1986). Anatomia dos animais domésticos. Rio de Janeiro: Interamericana.

Slatter, D. H. (2007). Manual de cirurgia de pequenos animais. São Paulo: Manole.

Withrow, S. J., Page, R. \& Vail, D. M. (2014). Small animal clinical oncology. St. Louis, USA: Elsevier Health Sciences.

Wright, T. \& Oblak, M. L. (2016). Surgical Skills Lymphadenectomy: Overview of surgical anatomy and removal of peripheral lymph nodes. Todays Veterinary Practice, 6(4):20-28.

Recebido: 13 de outubro, 2019.

Aprovado: 20 de novembro, 2019.

Publicado: 29 de fevereiro, 2020.

Licenciamento: Este artigo é publicado na modalidade Acesso Aberto sob a licença Creative Commons Atribuição 4.0 (CC-BY 4.0), a qual permite uso irrestrito, distribuição, reprodução em qualquer meio, desde que o autor e a fonte sejam devidamente creditados. 